
http://ejurnal.uij.ac.id/index.php/CONS

\title{
MODEL BIMBINGAN KELOMPOK TEKNIK DRAW a BRIDGE DALAM MENINGKATKAN MOTIVASI BELAJAR SISWA SMA DI BANJARMASIN
}

\author{
Riva Damayanti ${ }^{1}$, Zainal Fauzi ${ }^{2}$, Akhmad Rizkhi Ridhani ${ }^{3}$ \\ ${ }^{1}$ Mahasiswa Prodi Bimbingan dan Konseling, FKIP, UNISKA MAB, Indoensia \\ ${ }^{2}$ Dosen Prodi Bimbingan dan Konseling, FKIP, UNISKA MAB, Indonesia \\ ${ }^{3}$ Dosen Prodi Bimbingan dan Konseling, FKIP, UNISKA MAB, Indonesia \\ E-mail:damayantiriva@gmail.com, zainalf@uniska-bjm.ac.id, rizkhi.ridhani@gmail.com
}

\begin{abstract}
ABSTRAK
Berdasarkan hasil prapenelitian di SMA Muhammadiyah 1 Banjarmasin, peneliti mendapatkan hasil yaitu kurangnya motivasi belajar siswa. Untuk membantu meningkatkan motivasi belajar siswa ada berbagai macam cara salah satunya yaitu dengan menggunakan pelayanan BKP.Layanan BKP merupakan salah satu jenis layanan yang cocok digunakan untuk penanganan masalah yang sama pada lebih dari 1 orang. Pelayanan BKP dapat digunakan dengan berbagai metode/teknik. Salah satunya yaitu teknik draw a bridge. Metode dalam penelitian ini adalah R\&D dengan langkah pengembangan pendahuluan, pengembangan, uji ahli, terakhir revisi. Hasil dari validasi ahli menunjukan bahwa model ini layak dan hasil dari validasi praktisi model ini teruji kepraktisannya.
\end{abstract}

Kata Kunci: Bimbingan Kelompok,Motivasi, Draw a Bridge

\begin{abstract}
Based on the results of the pre-research, the researcher got the results, namely the lack of student motivation. To help increase students' motivation to learn, there are various ways, one of which is by using group guidance services. Group guidance services can be used with a variety of methods/techniques. One of them is the draw a bridge technique. The method in this research is R\&D with steps of preliminary development, development, expert testing, and lastly revision. The results of expert validation show that this model is feasible and the results of the practitioner's validation of this model can be used in the field.
\end{abstract}

Keywords : Group Guidance, Student Motivation, Draw a Bridge 


\section{PENDAHULUAN}

Sekolah merupakan suatu lembaga pendidikan yang menjadi wadah bagi para siswa untuk melaksanakan aktivitas belajar dan sekolah juga merupakan suatu lembaga pendidikan dimana manusia dididik dan dibina menjadi manusia yang pandai, produktif dan berkualitas. Dalam SISDIKNAS UUD No. 20 tahun 2003 (2013:17) Pendidikan nasional memiliki tujuan mencerdaskan kehidupan bangsa dan mengembangkan manusia seutuhnya, yaitu manusia yang beriman dan bertaqwa terhadap Tuhan Yang Maha Esa dan berbudi pekerti luhur, memiliki pengetahuan dan keterampilan kesehatan jasmani dan rohani, kepribadian yang mandiri serta tanggung jawab kemasyaratan dan kebangsaan. Strategi pelaksanaan pendidikan dilakukan dalam bentuk kegiatan bimbingan, pengajaran atau latihan. Dalam kegiatan bimbingan pada hakekatnya diberikan pemberian bantuan berupa arahan, motivasi, dan penyuluhan agar siswa mampu mengatasi, memecahkan dan menanggulangi kesulitan sendiri. Dengan adanya pendidikan, juga akan menimbulkan dalam diri seseorang untuk berlomba-lomba dan memotivasi diri untuk lebih baik dalam segala aspekkehidupannya.

Berdasarkan hasil pra penelitian yang dilakukan oleh peneliti padatanggal 14 Febuari 2020 dengan melakukan observasi dan pembagian angket DCM terhadap peserta didik di SMA Muhammadiyah 1 Banjarmasin. Peneliti mendapatkan hasil yaitu kurangnya motivasi belajar siswa yang ditandai dengan banyaknya yang memilih belajar hanya pada saat ujian, belajar tidak teratur waktunya, sering merasa malas belajar, kalau belajar sering mengantuk dan sering mendapat nilai dibawah kkm setiap ulangannya. Motivasi belajar siswa merupakan salah satu faktor yang penting untuk menentukan kualitas hasil pendidikan siswa. Menurut Hamzah (2013:1) motivasi adalah dorongan dasar yang menggerakan seseorang bertingkah laku. Keinginan dari dalam individu untuk bertindak dan berbuat dalam belajar karena adanya dorongan dari dalam atau dari luar individu sehingga individu dapat tergerak dengan keinginan diri sendiri untuk belajar dengan sendirinya. Siswa yang memiliki motivasi belajar tinggi akan mampu meraih prestasi belajar yang tinggi, tetapi sebaliknya, siswa yang motivasi belajarnya rendah cenderung mendapatkan prestasi belajar yang rendah pula dan akan mengalami kesulitan belajar yang lebih tinggi. Untuk menanggulangi atau membantu meningkatkan motivasi belajar siswa ada berbagai macam cara salah satunya yaitu dengan menggunakan pelayanan bimbingan kelompok. Prasetiya (2020:3) Layanan bimbingan kelompok merupakan salah satu jenis layanan yang paling cocok digunakan untuk penanganan masalah yang sifatnya sama dan yang bermasalah lebih dari satu orang. Pelayanan ini menggunakan berbagai macam metode/teknik. Penggunaan tehnik dalam kegiatan bimbingan kelompok mempunyai banyak fungsi selain dapat lebih memfokuskan kegaiatan bimbingan kelompok terhadap tujuan yang ingin dicapai tetapi juga dapat membuat suasana yang terbangun dalam kegiatan bimbingan kelompok agar lebih bergairah dan tidak cepat membuat siswa jenuh mengikutinya, seperti yang dikemukakan oleh Romlah dalam Irawan (2013:5) 'Bahwa teknik bukan merupakan tujuan tetapi sebagai alat untuk 
mencapai tujuan. Pemilihan dan penggunaan masing-masing teknik tidak dapat lepas dari kepribadian konselor, guru atau pemimpin kelompok'. Jadi jelas bahwa selain sebagai alat untuk mencapai tujuan, teknik penggunaan dan pemilihan juga harus disesuaikan dengan karakteristik konselor atau pemimpin kelompok. Salah satu metode/teknik menarik dan inovatif yang dapat digunakan dalam membantu peserta didik/konseli adalah dengan menggunakan Teknik Draw a Bridge.Menurut Hays \& Lyons dalam darewych (2014:11) teknik draw a bridge adalah pelayanan berbasis seni di mana individu menghasilkan gambar untuk mencerminkan pemikiran persepsi mereka tentang mereka di kehidupan masa lalu, sekarang dan masadepan. Teknik draw a bridge merupakan salah satu teknik dari Visual art penggunaan visual art telah banyak dilakukan oleh peneliti. Berikut beberapa penelitian dengan menggunakan visual art dalam penyelesaian masalah diantaranya penelitian yang dilakukan oleh Karyanti (2015) tentang konseling art dengan media gambar untuk meningkatkan self disclosure mahasiswa dan penelitian oleh Imami (2016) tentang efektivitas pendampingan kegiatan menggambar (dengan modifikasi art therapy) sebagai katarsis terhadap agresivitas, dll. Dengan penelitian penelitian tersebut dapat dijelaskan atau dibuktikan penggunaan visual art dalam mengatasi masalah dapat digunakan.

Penelitian ini bertujuan untuk mengetahui prosedur pengembangan modul bimbingan kelompok menggunakan teknik draw a bridge dalam meningkatkan motivasi siswa dan mengetahui kelayakan model yang dikembangkan menurut validasi ahli atau akademisi dan validasi praktisi selaku pelaksana di lapangan. Dengan berdasarkan penjelasan diatas peneliti tertarik untuk melakukan penelitian dan pengembangan modul bimbingan kelompok dengan teknik draw a bridge untuk meningkatkan motivasi belajar siswa SMA di Banjarmasin.

Penelitian ini diharapkan dapat menjadi model panduan pegangan guru BK untuk melaksanakan pelayanan dalam memberi bimbingan yang dapat mengembangkan potensi siswa kearah yang lebih baik dan membantu siswa mencapai pendidikan disekolah dengan lebih baik lagi dengan meningkatkan motivasi siswa disekolah dan diharapkan penelitian ini dapat menambah modul teknik yang dapat digunakan dalam bimbingan kelompok untuk meningkatkan motivasi belajarsiswa.

\section{METODE}

Penelitian ini menggunakan metode $\mathrm{R} \& \mathrm{D}$ atau research and development. Sugiyono (2014:297), menyatakan bahwa metode pendekatan research and development (R\&D), yaitu metode penelitian yang digunakan untuk menghasilkan produk tertentu, dan menguji keefektifan produk tersebut.Langkah-langkah penelitian dan pengembangan yang dilakukan adalah untuk menghasilkan produk tertentu dan untuk menguji kefektifan produk.Adapun produk yang dimaksud adalah model bimbingan kelompok menggunakan teknik draw a bridge yang berisi materi-materi terkait dengan meningkatkan motivasi belajar siswa. Berdasarkan langkah-langkah prosedur pengembangan borg and gall yang telahdimodifikasi, yaitu (1) Pendahuluan; (2) desain produk; (3) validasi ahli; dan (4) revisi model.Media pembelajaran modul 
pengembangan ini dibuat untuk menjadi pegangan guru sehingga cukup divalidasi oleh 2 orang akademisi BK dengan kualifikasi S2 linier bimbingan dan konseling dan 5 guru bimbingan dan konseling masing-masing dari 5 sekolahan yang berbeda yang mewakilidari masing masing di 5 kecamatan di Banjarmasin. Pengukuran keabsahan data pada penelitian ini dilakukan dengan triangulasi. Sugiyono (2016: 241) mengatakan bahwa triangulasi adalah teknik pengumpulan data yang bersifat menggabungkan dari berbagai teknik pengumpulan data dan sumber data yang telah ada. Uji keabsahan data pada penelitian kualitatif dengan menggunakan triangulasi akan lebih meningkatkan kekuatan data apabila dibandingkan dengan satu pendekatan. Dalam penelitian ini, peneliti menggunakan teknik keabsahan data dengan triangulasi teknik. Triangulasi teknik yaitu peneliti menggunakan teknik pengumpulan data yang berbeda-beda untuk mendapatkan data dari sumber yang sama. Teknik pengumpulan data yang dimaksud berupa wawancara, observasi, dan dokumentasi untuk sumber data yang sama secara serentak (Sugiyono, 2016: 241). Penelitian ini menggunakan tekni kanalisis data kualitatif. Miles and Huberman dalam Sugiyono (2013: 337) mengemukakan bahwa aktivitas dalam analisis data kualitatif meliputi pengumpulan data, reduksi data, penyajian data, dan penyimpulan data. Selain menggunakan teknik analisis data kualitatif, penelitian ini juga menggunakan teknik statistic deskriptif. Menurut Arikunto (2010:3) bahwa: "Penelitian deskriptif adalah penelitian yang dimaksudkan untuk menyelidiki keadaan, kondisi atau hal-hal lain yang sudah disebutkan, yang hasilnya dipaparkan dalam bentuk laporanpenelitian. Peneliti tidak mengubah, menambah, atau mengadakan manipulasi terhadap objek atau wilayah penelitian. Peneliti hanya memotret apa yang terjadi pada diri objek atau wilayah yang diteliti, kemudian memaparkan apa yang terjadi dalam bentuk laporan penelitian secara lugas, seperti apa adanya."

\section{HASIL DAN PEMBAHASAN}

Pada tahap pendahuluan yaitu tahap prapenelitian untuk mengetahui kondisi objektif dilapangan peneliti mendapatkannya dari hasil angket DCM yang telah dibagikan pada siswa. Masalah-masalah tersebut meliputi, siswa belajar hanya saat ada ujian, siswa belajar tidak teratur waktunya, siswa sering merasa malas belajar, siswa kalau belajar sering mengantuk, siswa sering mendapat nilai dibawah KKM lalu didapatkanlah hasil rendahnya motivasi belajar siswa. Setelah tahap pendahuluan selesai, selanjutnya dilakukan tahap pengembangan. Pada tahap ini dilakukan pembuatan kerangka model, matrix model dan panduan model. Model awal yang telah dibuat selanjutnya divalidasi oleh validator akademisi atau ahli. Tahap pertama oleh validasi akademisi atau ahli tahap 1 dan mendapatkan skor 20 dengan beberapa catatan yang segera direvisi. Setelah merevisi model sesuai dengan masukan validator akademisi tahap 1, selanjutnya dilanjutkan denganvalidasi validor akademisi tahap 2 dan mendapatkan skor 27 tanpa catatan revisi dengan kategori penilaian sangat baik/sangat tepat/sangat sesuai dan disimpulkan model ini sudah siap digunakan dengan sedikit perbaikan sesuai saran.

Setelah itu model di uji validasi oleh praktisi/guru BK di sekolah di masing masing 
kecamatan. Totalan skor yang didapatkan yaitu dari sekolahBanjarmasin Barat di SMA Muhammadiyah 1 mendapatkan skor 23, Banjarmasin Timur di SMA Negeri 3 Banjarmasin mendapatkan skor 24, Banjarmasin Utara di SMA Negeri 8 Banjarmasin dengan skor 21, Banjarmasin Selatan di SMA Negeri 13 Banjarmasin dengan skor23, Banjarmasin Tengahdi SMA Negeri 2 Banjarmasindengan skor 22 yang manajumlah skor tersebut dikategorikan dalam penilaian sangat baik atau sangat tepat atau sangat sesuai dan dapat disimpulkan model ini sudah siap digunakan dengan sedikit perbaikan sesuai saran.

Pada tahap revisi berdasarkan masukan dari validator terhadap model yang dikembangkan peneliti terkait dengan pengembangan model bimbingan kelompok dengan teknik drawa bridge dalam meningkatkan motivasi belajar siswa, berikut adalah beberapa perbaikan yang dilakukan oleh peneliti berdasarkan masukan validator:

\section{Tabel Hasil Perbaikan Model Bimbingan Kelompok Dengan Teknik DrawA Bridge Dalam Meningkatkan Motivasi BelajarSiswa}

\section{Model Sebelum Perbaikan}

1. Penjabaran misi tidak berbentuk list dan bahasa visi tidak disusun

dengansingkat dan jelas

2. Isi layanan bimbingan kelompok dengan teknik draw a bridge kurang tepat karna dituliskan bidang-bidang bimbingan dan konseling. Tidak ada diagram alir yangdi masukan untuk menjelaskan cara kerja teknik drawa bridge dalam meningkatkan motivasi belajar.

3. Teknik draw a bridge hanya dilakukan di tahapan ke 5 dan didalam sesi kegiatan langkah - langkah melaksanakan teknik initidak dijabarkan secara rinci.

4. Tidak ada worksheet sebagai lembar kerja yang akan digunakan oleh anggota kelompok pada model layanan bimbingan kelompok denganteknik draw a bridge

\section{Model Sesudah Perbaikan}

1. Bahasa misi sudah diperbaiki menjadi bentuk list dan bahasa visisudah disusun menjadi singkat dan jelas.

2. Isi layanan bimbingan kelompok dengan teknik draw a bridge sudah diperbaiki menjadi deskripsi singkat mengenai model bimbingan kelompok teknik draw a bridge. Telah dimasukan diagram alir untuk memperjelas cara kerja bimbingan kelompok teknik draw a bridge dalam meningkatkan mootivasi belajar siswa

3. Teknik draw a bridge telah dimasukan disetiap sesi didalam tahapan kegiatan dan langkah-langkah dalam sesi kegiatan telah dirincikan menjadi 2 tahapan yaitu tahapan umum dan tahapan khusus

4. Telah dimasukan worksheet untuk melaksanakan draw a bridge pada lampiran pedoman model 


$\begin{array}{lll}\text { 5. Belum ada } \quad \text { penjelasan rinci } & \text { 5. Telah dijelaskan objek apa yang akan } \\ \text { mengenai menggambar objek apa saat } & \text { di gambar pada model panduan model } \\ \text { pelaksaan teknik draw a bridge } & \text { bimbingan kelompok denganteknikdraw a } \\ \text { padapanduan Bimbingan kelompok dengan } & \text { bridge } \\ \text { teknik draw abridge } & \end{array}$

\section{Tidak menggunakan evaluasi yang} beracuan pada POP BK

7. Belum dilampirkan RPL dalam model

8. Belum dilampirkan skala motivasi belajar dalam panduan model

9. Belum dilampirkan angket laiseg sebagai sebagai instrumen penilaian evaluasi hasil tiap sesi dalam panduan model

Setelah revisi berdasarkan masukan dari validator ahli atau akademisi dan praktisi didapatkan hasil skor dari validasi keduanya mendapatkan penilaian dalam kategori penilaian sangat baik atau sangat tepat atau sangat sesuai dan disimpulkan model ini sudah siapdigunakan dengan sedikit perbaikan sesuai saran. Berdasarkan hasil penskoran tersebut dapat di nyatakan bahwa model bimbingan kelompok dengan teknik draw a bridge dalam meningkatkan motivasi belajar siswa sudah layak menurut validator ahli atau akademisidalam hal kelayakan model dan sudah layak menurut validator praktisi selaku pelaksana/praktisi dilapangan.

\section{SIMPULAN}

Penelitian dan pengembangan ini menghasilkan produk berupa model panduan bimbingan kelompok dengan teknik draw a bridge dalam meningkatkan motivasi belajar siswa. Tahapan yang dilakukan untuk menghasilkan model bimbingan kelompok adalah sebagai berikut: a) tahap
6. Telah menggunakan evaluasi dengan beracuan pada evaluasi POP BK

7. Sudah dilampirkan RPL dalam model

8. Sudah dilampirkan skala motivasi belajar dalam panduan model

9. Sudah dilampirkan angket laiseg sebagai instrumen penilaian evaluasi hasil setiap sesi dalam panduan model

pendahuluan; b) tahap pengembangan; c) tahap uji ahli; dan d) tahaprevisi.

Berdasarkan validasi ahli/akademisi dan praktisi, dapat diketahui hasil validasi ahli/akademisi dari validasi tahap 1 mendapatkan nilai 20 dengan catatan revisi. Setelah direvisi lalu dilakukan validasi tahap 2 dengan mendapatkan nilai 27 tanpa catatan revisi. Dan hasil dari validasi praktisi mendapatkan nilai skor 23, 24, 21, 23, 22 tanpa catatan revisi. Jumlah skor dari validasi ahli dan praktisi tersebut dikategorikan dalampenilaian sangat baik/sangat tepat/sangat sesuai dan dapat disimpulkan model ini sudah siap digunakan dengan sedikit perbaikan sesuaisaran. Saran dalam penelitian ini karna peneliti hanya meneliti kelayakan dari pengembangan modul bimbingan kelompok dengan teknik draw a bridge dalam meningkatkan motivasi belajar siswa, namun karena keterbatasan bahwa penelitian belummencapai pada pengujian efektifitas dari produk media layanan, maka peneliti mempersilakan peneliti lain untuk melakukan penelitan lanjutan. 


\section{DAFTAR PUSTAKA}

Arikunto, S. (2010). Prosedur Penelitian Suatu Pendekatan Praktik. Jakarta: Rineka Cipta.

Darewych, O. (2014). The Bridge Drawing with Path Art-Based Assessment: Measuring Meaningful Life Pathways in Higher Education Students. Expressive Therapies

Dissertations.Diaksesdari:https://digital commons. lesley.edu/expressive dissert ations/44/

Hamzah. B. Uno. (2013). Teori Motivasi dan Pengukurannya. Jakarta: Bumi Aksara.

Imami, A.D., Sulistiyorini, D., Setiyowati, N. (2016). Efektivitas Pendampingan Kegiatan Menggambar (Dengan Modifikasi Art Therapy) Sebagai Katarsis Terhadap Agresivitas. Jurnal Sains Psikologi. 5(2).

Irawan, E. (2013). Efektivitas Teknik Bimbingan Kelompok Untuk Meningkatkan Konsep Diri Remaja (Studi Pre-Eksperimen Pada Siswa Kelas X SMK Yapema Gadingrejo Lampung). Jurnal Bimbingan dan Konseling "PSIKOPEDAGOGIA". 2(1), 44-54

Karyanti (2015) Konseling Art Dengan Media Gambar Untuk Meningkatkan Self Disclosure Mahasiswa. Anterior Jurnal. 15(1), 55-61

Prasetiya, Y. T. (2020). Pengaruh Layanan Bimbingan Kelompok Menggunakan Teknik Karyawisata Terhadap Tanggung Jawab Belajar Siswa Kelas X Smk Pgri 2 Kediri Tahun Pelajaran 2019/2020. Skripsi, Universitas Nusantara PGRI Kediri. Diakses dari http://simki.unpkediri.ac.id/mahasiswa /file artikel/2020/14.1.01.01.0060.pdf

Sugiyono. (2013). Metode Penelitian Pendidikan Pendekatan Kuantitatif,
Kualitatif, dan R\&D. Bandung: Alfabeta.

Sugiyono. (2014). Metode Penelitian Pendidikan Pendekatan Kuantitatif, Kualitatif, dan R\&D. Bandung: Alfabeta.

Sugiyono. (2016). Metode Penelitian Kuantitatif, Kualitatif dan R\&D. Bandung: PT Alfabet.

UUD RI. (2013). Undang-undang SISDIKNAS (sistem Pendidikan Nasional) No. 20 Tahun 2003. Jakarta: Sinar Grafika. 